\title{
Komparasi dan Optimasi Model Propagasi pada Sistem Komunikasi Seluler di Kota Palembang
}

\author{
Mohammad Fadhli* dan Sopian Soim \\ Program Studi Teknik Telekomunikasi, Jurusan Teknik Elektro, Politeknik Negeri Sriwijaya, \\ Palembang, Sumatera Selatan, Indonesia \\ *Corresponding author, e-mail: mohammad.fadhli@polsri.ac.id
}

\begin{abstract}
Abstrak-Terdapat berbagai macam model propagasi yang dapat digunakan untuk memprediksi path loss. Setiap model propagasi diklasifikasikan berdasarkan kategori lingkungannya. Pembagian kategori lingkungan ini bersifat subjektif, sehingga untuk mendapatkan prediksi yang akurat diperlukan pemilihan kategori lingkungan yang tepat. Penelitian ini membandingkan empat jenis model propagasi dengan hasil pengukuran RSL pada lima site di Kota Palembang. Model yang dibandingkan adalah Okumura Hata, ECC33, Ericsson dan SUI. Berdasarkan komparasi menggunakan parameter RMSE, Kota Palembang menurut model Okumura Hata termasuk dalam kategori large urban. Sedangkan pada model ECC-33 termasuk kategori medium urban. Pada model Ericsson termasuk kategori suburban, dan pada model SUI termasuk dalam tipe terrain A. Dari perbandingan keempat model berdasarkan RMSE dan standar deviasi, diketahui bahwa pada hasil pengukuran lima site di Kota Palembang, model ECC-33 memiliki akurasi yang tinggi dengan RMSE 3,28 dB dan standar deviasi 2,74 dB. Setelah dioptimasi, model Okumura Hata juga memberikan akurasi prediksi yang tinggi, dengan RMSE 1,75 dB dan standar deviasi 0,76 dB. Sehingga disarankan untuk menggunakan model ECC-33 medium urban atau model Okumura Hata large urban yang telah dioptimasi untuk mempredikasi path loss di Kota Palembang.
\end{abstract}

Kata Kunci : Model Propagasi, Optimasi, Kategori Lingkungan, Okumura Hata, ECC-33, Ericsson, SUI

\begin{abstract}
Various propagation models can be used to predict path loss. Each propagation model is classified according to its environment categories. These environment categories are purely subjective, therefore to get accurate predictions, proper environment category selection is needed. In this paper, four propagation models are compared with RSL measurements at five sites in Palembang City. The models being compared are Okumura Hata, ECC-33, Ericsson, and SUI. Based on comparison using RMSE parameters, large urban is the appropriate environment category for Palembang City in the Okumura Hata model. For ECC-33, the appropriate environment category is medium urban. In the Ericsson model, the appropriate category is suburban, and terrain type A for SUI model. From the comparison of four models based on RMSE and standard deviations, it is known that for measurement results of five sites in Palembang City, the ECC-33 model has high accuracy with RMSE of 3,28 dB and standard deviation of 2,74 dB. After optimization, the Okumura Hata model provides an RMSE of 1,75 dB and a standard deviation of 0,76 dB. It is recommended to use the Medium Urban ECC-33 model or the optimized Large Urban Okumura Hata model to predict path loss in Palembang City.
\end{abstract}

Keywords : Propagation Models, Optimization, Environment Categories, Okumura Hata, ECC-33, Ericsson, SUI.

\section{Pendahuluan}

Sistem komunikasi seluler merupakan salah satu sarana komunikasi yang banyak digunakan pada saat ini. Banyaknya jumlah pengguna harus diikuti dengan layanan yang maksimal dari operator. Layanan yang maksimal dapat diperoleh melalui proses perencanaan dan optimasi jaringan secara terukur dan akurat.
Diantara bentuk kegiatan perencanaan dan optimasi jaringan seluler yang penting dilakukan adalah memprediksi daya terima sinyal dalam suatu sel. Hal ini perlu dilakukan agar dapat diprediksi sejauh mana coverage area suatu sel, sebab perencanaan coverage area yang baik akan berpengaruh terhadap kualitas layanan yang diberikan.

Daya terima sinyal dapat diprediksi berdasarkan 
nilai path loss. Terdapat beberapa model propagasi yang dapat digunakan untuk memprediksi path loss. Diantaranya adalah model Okumura Hata [1], Stanford University Interim (SUI), ECC-33[2], Ericsson [3] dan lain-lain. Model-model tersebut didapatkan berdasarkan serangkaian pengukuran path loss pada satu wilayah tertentu yang kemudian disesuaikan dengan karakteristik sistem pengukuran seperti karakteristik wilayah, tinggi antena, gain antena dan lain-lain [4].

Dalam proses perencanaan dan optimasi sistem seluler, perlu dipilih model propagasi yang paling sesuai untuk diterapkan di suatu wilayah, sehingga didapatkan hasil prediksi yang tidak berbeda jauh dengan hasil pengukuran. Sebab model yang cocok diterapkan di satu wilayah belum tentu cocok digunakan di wilayah yang lain, jika wilayah tersebut memiliki karakteristik yang berbeda.

Model propagasi diklasifikasikan berdasarkan kategori lingkungan. Sebagai contoh, model Okumura Hata dibagi menjadi urban, suburban dan open area [1]. Sedangkan model ECC-33 dibedakan menjadi dua kategori, yaitu large urban dan small urban [2]. Pembagian kategori lingkungan ini bersifat subjektif, sebab standar besar dan kecilnya kota harus mengikuti standar dimana model ini dikembangkan [4]. Jadi untuk mendapatkan prediksi yang akurat, harus digunakan model dengan kategori lingkungan yang tepat.

Berbagai penelitian telah membahas model propagasi yang tepat untuk diterapkan di berbagai daerah. Penelitian-penelitian tersebut dilakukan dengan cara membandingkan daya sinyal dari hasil pengukuran dengan daya sinyal dari hasil prediksi menggunakan berbagai model propagasi.

Penelitian pada artikel [5-7] mengevaluasi model propagasi di wilayah Nigeria, sedangkan penelitian [8] mengevaluasi untuk wilayah Kanakata state India. Pada penelitian [9] dilakukan analisis komparatif dari beberapa model propagasi untuk jaringan LTE di NCR region Delhi India, dan didapatkan kesimpulan bahwa model Ericsson paling cocok untuk diterapkan di daerah tersebut.

Beberapa penelitian juga telah dilakukan untuk memilih model propagasi yang paling tepat untuk berbagai kota di Indonesia. Pada penelitian [10] dibandingkan beberapa model propagasi untuk di terapkan di Kota Tarakan Kalimantan Utara. Didapatkan kesimpulan bahwa model COST-231 Hata paling sesuai di Kota Tarakan. Selain itu, pada penelitian ini juga dilakukan optimasi terhadap model COST-231 Hata untuk meningkatkan akurasi model.

Pada penelitian sebelumnya juga telah dibandingkan beberapa model propagasi untuk Kota Palembang. Artikel [11] membandingkan dua jenis model propagasi, yaitu model PCS Extension to Hata dan model SUI. Diantara kedua model tersebut, model SUI lebih mendekati hasil pengukuran daya terima sinyal di lapangan.

Untuk mengembangkan hasil penelitian yang ada pada artikel [11], pada artikel ini akan dibandingkan hasil pengukuran daya terima dengan beberapa model lainnya, sehingga didapatkan model propagasi yang paling sesuai di Kota Palembang. Model yang akan dibandingkan adalah model Okumura Hata, model ECC-33, model Ericsson dan model SUI. Dari tiap model, ditentukan terlebih dahulu kategori lingkungan yang paling tepat untuk diterapkan di Kota Palembang. Setelah itu dilakukan analisis komparasi antara hasil prediksi dengan hasil pengukuran berdasarkan nilai root mean square error (RMSE) dan standar deviasi. Hal ini bertujuan untuk menemukan model yang paling akurat. Setelah itu dilakukan optimasi model jika diperlukan.

\section{Path Loss Pada Sistem Komunikasi Nirkabel}

Path loss merupakan atenuasi yang dialami oleh daya sinyal selama merambat di saluran transmisi. Besarnya nilai path loss bisa didapatkan dengan menghitung selisih antara daya pancar efektif (ERP) dengan daya yang ditangkap oleh antena penerima. Path loss dapat dihitung menggunakan persamaan berikut [12]:

$$
P L(d B)=E R P-P_{r}
$$

Dimana ERP (Effective Radiated Power) merupakan daya pancar efektif dalam dBm dan $P_{r}$ merupakan daya terima atau received signal level (RSL) dalam dBm. Besarnya ERP dapat dihitung menggunakan persamaan berikut [1]:

$$
E R P(d B m)=P_{t}-G_{t}-L_{c}-L_{o t}
$$

Dimana $P_{t}$ merupakan daya pancar dalam $\mathrm{dBm}$, $G_{t}$ merupakan gain antena pemancar dalam dB, serta $L_{c}$ dan $L_{o t}$ merupakan loss konektor dan loss dari faktor-faktor lain dalam satuan $\mathrm{dB}$. 


\section{Model Propagasi}

Secara umum terdapat beberapa jenis model propagasi yang dapat digunakan untuk memprediksi path loss. Salah satunya adalah model empiris. Model empiris merupakan suatu model yang digunakan untuk memprediksi path loss pada suatu karakteristik lingkungan tertentu berdasarkan parameter-parameter sistem telekomunikasi seperti ketinggian antena, frekuensi kerja, gain antena dan lain sebagainya [13].

Model empiris didapatkan dari serangkaian hasil pengukuran path loss yang kemudian dibangun menjadi suatu fungsi matematis dengan parameter-parameter yang disesuaikan dengan kondisi lingkungan tertentu, frekuensi serta parameter-parameter lainnya, sehingga dapat meminimalkan error diantara model dan hasil pengukuran [13].

\subsection{Model Okumura Hata}

Model Okumura Hata merupakan salah satu model empiris yang didasarkan kepada serangkaian hasil pengukuran path loss di lingkungan urban. Model ini cocok untuk digunakan pada jangkuan frekuensi $150-1000 \mathrm{MHz}$ dan 1500-2000 MHz. Model ini dapat memprediksi path loss dalam jarak 1-20 km. Berdasarkan model ini, besarnya path loss diantara antena pemancar dan antena penerima dinyatakan dengan persamaan berikut [1]:

$$
\begin{aligned}
P L(d B)= & \left(69,55+26,16 \log f_{c}-\right. \\
& \left.13,82 \log h_{t}\right)+(44,9- \\
& \left.6,55 \log h_{t}\right) \log d-C
\end{aligned}
$$

Dimana $f_{c}$ (dalam MHz) merupakan frekuensi, $h_{t}$ (dalam meter) merupakan tinggi antena base station dan $d$ merupakan jarak antara antena base station dengan antena mobile station dalam meter. Variabel $C$ merupakan fungsi ketinggian antena mobile station berdasarkan kategori lingkungan yang terdiri dari suburban, open area dan urban. Untuk kategori suburban dapat dihitung menggunakan persamaan (4):

$$
C=2 \log ^{2}\left(\frac{f_{c}}{28}\right)+5,4
$$

Sedangkan untuk kategori open area dihitung menggunakan persamaan (5):

$$
C=4,78 \log ^{2} f_{c}+18,33 \log f_{c}+40,94
$$

Untuk kategori urban terbagi lagi menjadi kota besar dan kota kecil. Untuk kota besar dengan $f_{c} \geq$ $300 \mathrm{MHz}$ dinyatakan dengan persamaan (6)

$$
C=4,78 \log ^{2} f_{c}+18,33 \log f_{c}+40,94
$$

Sedangkan untuk kota kecil dapat dihitung menggunakan persamaan (7):

$$
\begin{aligned}
C=\left(1,1 \log f_{c}-0,7\right) h_{r} \\
-\left(1,56 \log f_{c}-0,8\right)
\end{aligned}
$$

Dimana $h_{r}$ (dalam meter) merupakan tinggi antena mobile station [1].

\subsection{Model ECC-33}

Model ECC-33 dikembangkan oleh Electronic Communication Committee (ECC) yang merupakan ekstrapolasi dari data pengukuran Okumura Hata. Model ini diadaptasi untuk kategori kota medium dan kota besar. Pada model ini terdapat faktor koreksi untuk suburban dan open area. Model ini dapat digunakan untuk prediksi path loss pada frekuensi $700 \mathrm{MHz}$ sampai 3,5 GHz. Berdasarkan model ECC-33 besarnya path loss dihitung dengan persamaan berikut [2]:

$$
\begin{aligned}
& P L(d B)=A_{F S}+A_{B M}-G_{T}-G_{R} \\
& A_{F S}=92,4+20 \log d+20 \log f_{c} \\
& A_{B M}=20,41+9,83 \log d+7,89 \log f_{c}+ \\
& 9,56\left(\log f_{c}\right)^{2} \\
& G_{T}=\log \frac{h_{t}}{200}\left[13,98+5,8(\log d)^{2}\right]
\end{aligned}
$$

$A_{F S}$ merupakan atenuasi sinyal dalam kondisi free space, dimana $d$ dan $f_{c}$ merupakan jarak dan frekuensi yang diukur dalam satuan $\mathrm{km}$ dan $\mathrm{GHz}$.

Variabel $G_{R}$ dibagi berdasarkan kategori lingkungan untuk kota menengah (medium sized urban) dan kota besar. Untuk kota besar $G_{R}$ dihitung menggunakan persamaan (12), sedangkan untuk kota kecil dapat dihitung dengan persamaan (13):

$$
\begin{gathered}
G_{R}=0,759 h_{r}-1,862 \\
G_{R}=\left[42,57+13,7 \log f_{c}\right]\left[\log h_{r}-0,585\right]
\end{gathered}
$$




\subsection{Model Ericsson}

Model ini merupakan pengembangan dari model Okumura Hata agar dapat digunakan di frekuensi yang lebih tinggi. Model ini dikembangkan oleh Ericsson company. Path loss pada model ini dihitung menggunakan persamaan berikut [14]:

$$
\begin{aligned}
P L(d B)= & a_{0}+a_{1} \log d+a_{2} \log h_{t}+ \\
& a_{3} \log h_{t} \log d-3,2\left(\log (11,75)^{2}\right)+ \\
& g(f)
\end{aligned}
$$

$g(f)=44,49 \log f_{c}-4,78\left(\log \left(f_{c}\right)\right)^{2}$

Nilai variabel $a_{0}, a_{1}, a_{2}$ dan $a_{3}$ berbeda berdasarkan kategori lingkungannya, yang dibedakan menjadi urban, suburban dan rural. Masing-masing nilai untuk tiap kategori lingkungan terdapat pada Tabel 1.

Tabel 1. Parameter Model Ericsson[15]

\begin{tabular}{|c|c|c|c|c|}
\hline & $a_{0}$ & $a_{1}$ & $a_{2}$ & $a_{3}$ \\
\hline Urban & 36,2 & 30,2 & 12,0 & 0,1 \\
Suburban & 43,20 & 68,93 & 12,0 & 0,1 \\
Rural & 45,95 & 100,6 & 12,0 & 0,1 \\
\hline
\end{tabular}

\subsection{Model SUI}

Model SUI dikembangkan dari kolaborasi antara Stanford University dengan IEEE 802.16 group. Model ini dibagi menjadi tiga kategori, yaitu kategori A, B dan C. Kategori A digunakan untuk wilayah dengan path loss paling besar diantara kategori yang lain, yang dapat terjadi pada wilayah berbukit yang memiliki konsentrasi vegetasi sedang hingga berat. Kategori B untuk wilayah dengan path loss sedang pada wilayah yang memiliki vegetasi sedang atau wilayah yang memiliki vegetasi berat dengan daratan yang datar. Kategori $\mathrm{C}$ untuk wilayah dengan path loss kecil pada wilayah yang datar dan vegetasi yang ringan.

Path loss pada model SUI dapat dihitung menggunakan persamaan-persamaan berikut ini [2].

$P L(d B)=A+B+X_{f}+X_{h}+s$

$A=20 \log \left(\frac{4 \pi d_{0}}{\lambda}\right)$

$B=10 \gamma \log \left(\frac{d}{d_{0}}\right)$

$\gamma=a-b\left(h_{t}\right)+\left(\frac{c}{h_{t}}\right)$
$X_{f}=6 \log \left(\frac{f_{c}}{2000}\right)$

$X_{h}=\left\{\begin{array}{lr}-10,8 \log \left(\frac{h_{r}}{2}\right), & \text { terrain } A, B \\ -2 \log \left(\frac{h_{r}}{2}\right), & \text { terrain } C\end{array}\right.$

Berdasarkan persamaan (15) sampai (20), variabel A merupakan free space loss yang diukur dalam $\mathrm{dB} . \lambda$ merupakan panjang gelombang dalam meter dan $d_{0}$ merupakan jarak referensi (dalam meter). $\gamma$ merupakan path loss eksponen, sedangkan $X_{f}$ merupakan faktor koreksi frekuensi dan $X_{h}$ merupakan faktor koreksi tinggi antena penerima. Variabel $s$ merupakan variabel acak akibat adanya large scale fading. Nilai variabel $s$ serta $a, b$ dan $c$ dibedakan berdasarkan kategori lingkungan (terrain) yang terdapat pada Tabel 2 [2].

Tabel 2. Parameter Terrain Model SUI

\begin{tabular}{|c|c|c|c|}
\hline $\begin{array}{c}\text { Parameter } \\
\text { Model }\end{array}$ & Terrain A & Terrain B & Terrain C \\
\hline a & 4,6 & 4 & 3,6 \\
b & 0,0075 & 0,0065 & 0,005 \\
$\mathrm{c}$ & 12,6 & 17,1 & 20 \\
$\mathrm{~s}$ & 10,6 & 9,4 & 8,2 \\
\hline
\end{tabular}

\section{Metode Penelitian}

\subsection{Sistem Pengukuran}

Prediksi path loss dari tiap model dievaluasi berdasarkan data path loss hasil pengukuran. Pengukuran path loss dilakukan dengan cara mengukur daya yang diterima oleh perangkat mobile station pada jarak tertentu dari antena base station. Path loss hasil pengukuran didapatkan dengan cara mencari selisih antara daya yang diterima dengan daya efektif (ERP) yang dipancarkan oleh antena base station .

Artikel ini menggunakan data pengukuran yang sama dengan artikel [11]. Penelitian dilakukan pada lima site di Kota Palembang. Kelima site tersebut terdapat pada lokasi sebagai berikut:

1. Jl. Putri Rambut Selako, Gg. Kolam Sikam, Kel. Bukit Lama.

2. Jl. Tj. Pandan, RT. 07, RW. 01, Suka Maju, Sako.

3. Jl. HBR Motik, Kp. Minterejo, KM.8, No. 1880, Karya Baru, Kec. Alang-Alang Lebar.

4. Jl. Jendral Ahmad Yani, Gg. PU, 7 Ulu, Kec. Seberang Ulu 1.

5. Jl. Bangau, No. 40, 9 Ilir, Kec. Ilir Timur 2. 
Posisi dari tiap site dapat dilihat pada Gambar 1.

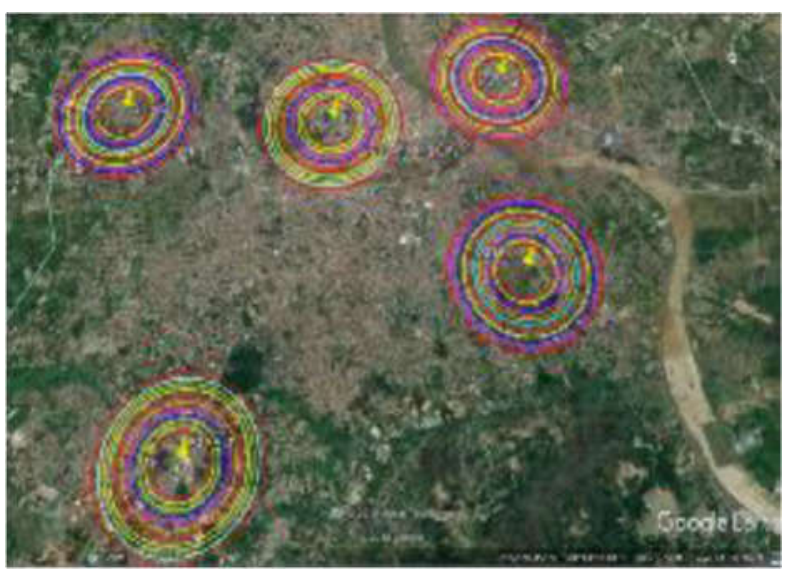

Gambar 1. Posisi Site

Parameter yang perlu diperhatikan dalam proses pengukuran dan pemodelan diantaranya adalah jarak, frekuensi, ketinggian antena dan daya pancar. Pengukuran daya terima dilakukan tiap jarak 100 meter dari posisi base station. Pengukuran dimulai dari jarak 500 meter sampai 1500 meter, sehingga terdapat sebelas titik pengukuran pada tiap site. Sinyal yang diukur bekerja pada frekuensi 900 MHz. Ketinggian posisi antena pada tiap base station berkisar dari $30 \mathrm{~m}-45 \mathrm{~m}$ dengan ketinggian antena mobile station $1 \mathrm{~m}$. Semua base station memancarkan sinyal dengan daya sebesar $20 \mathrm{dBm}$. Daya diterima diukur menggunakan perangkat lunak G-Net Track.

\subsection{Metode Evaluasi Model Prediksi Path Loss}

Pada penelitian ini, daya terima (RSL) hasil pengukuran dibandingkan dengan hasil prediksi dari model Okumura Hata, ECC-33, Ericsson dan SUI. Prediksi RSL dapat diketahui dari selisih antara ERP dengan perhitungan path loss pada tiap model. Prediksi path loss dengan model Okumura Hata dihitung menggunakan persamaan (3) sampai persamaan (7). Prediksi dengan model ECC-33 dihitung menggunakan persamaan (8) sampai persamaan (13). Model Ericsson dihitung menggunakan persamaan (14) dan persamaan (15). Sedangkan model SUI dihitung menggunakan persamaan (16) sampai persamaan (21).

Pada tahap pertama terlebih dahulu ditentukan kategori lingkungan yang tepat dari tiap model untuk Kota Palembang. Hal ini dilakukan dengan cara membandingkan hasil pengukuran dengan hasil prediksi di berbagai kategori lingkungan pada tiap model. Pada tahap kedua dilakukan perbandingan antar model yang berbeda. Hal ini bertujuan untuk menemukan jenis model yang memiliki akurasi paling tinggi.

Parameter yang digunakan untuk mengevaluasi akurasi model adalah nilai root mean square error (RMSE) dan standar deviasi dari selisih (error) hasil prediksi dengan hasil pengukuran. RMSE merupakan ukuran magnitudo rata-rata error antara nilai yang diprediksi oleh model path loss dengan hasil pengukuran. Sedangkan standar deviasi merupakan ukuran sebaran error hasil prediksi terhadap nilai rata-rata error [16]. Model yang dipilih adalah model dengan RMSE dan standar deviasi terkecil

Nilai RMSE dihitung menggunakan persamaan (22) [6]:

$R M S E=\sqrt{\frac{1}{n} \sum_{i=1}^{n}\left|R S S M_{i}-R S S P_{i}\right|^{2}}$

Dimana RSSM merupakan besarnya daya terima yang terukur pada tiap titik pengukuran dan RSSP merupakan daya terima yang diprediksi. Variabel $n$ menunjukkan jumlah titik pengukuran pada tiap site.

Nilai standar deviasi dihitung menggunakan persamaan berikut [13]:

$$
\begin{aligned}
& S D=\sqrt{\frac{1}{n} \sum_{i=1}^{n}\left(\left|R S S M_{i}-R S S P_{i}\right|-M E\right)^{2}} \\
& M E=\frac{1}{n} \sum_{i=1}^{n}\left|R S S M_{i}-R S S P_{i}\right|
\end{aligned}
$$

dimana $M E$ merupakan rata-rata error model propagasi pada tiap site pengukuran. Model yang layak digunakan adalah model yang memiliki RMSE $\leq 6 \mathrm{~dB}$ dan standar deviasi $\leq 10 \mathrm{~dB}$ [17].

\section{Hasil dan Pembahasan}

\subsection{Evaluasi Kategori Lingkungan}

Pada bagian ini perbandingan nilai RMSE di berbagai kategori lingkungan pada tiap model disajikan dalam bentuk tabel. Hasil perbandingan dapat dilihat pada Tabel 3 sampai Tabel 6 .

Pada Tabel 3 ditunjukkan perbandingan RMSE pada model Okumur Hata untuk kategori lingkungan large urban, small urban, suburban dan open area. Kategori large urban memiliki rata-rata RMSE sebesar 22,82 dB, small urban sebesar 22,86 $\mathrm{dB}$, sub urban sebesar $34,05 \mathrm{~dB}$ dan open area sebesar 160,89 dB. Sehingga dapat diketahui 
bahwa pada model Okumura Hata Kota Palembang termasuk kepada kategori lingkungan large urban.

Nilai RMSE untuk model ECC-33 pada Tabel 4 menunjukkan bahwa kategori lingkungan medium urban memiliki rata-rata RMSE di seluruh site sebesar 3,28 dB. Sedangkan pada kategori large urban memiliki rata-rata RMSE sebesar 26,17 dB. Jadi dapat disimpulkan bahwa pada model ECC-33, kategori lingkungan yang tepat untuk Kota Palembang adalah medium urban.

Pada Tabel 5 disajikan nilai RMSE pada tiap site menggunakan model Ericsson dengan kategori lingkungan urban, suburban dan rural. Dapat diketahui bahwa kategori urban memiliki rata-rata RMSE di seluruh site sebesar 11,78 dB. Kategori sub urban memiliki rata-rata RMSE sebesar 7,55 $\mathrm{dB}$, sedangkan kategori rural memiliki rata-rata RMSE sebesar 10,32 dB. Jadi dapat disimpulkan bahwa pada Model Ericsson Kota Palembang termasuk kepada kategori sub urban.

Untuk model SUI, nilai RMSE pada tiap site dapat dilihat di Tabel 6. Pada model ini dibagi menjadi tiga tipe terrain, yaitu tipe A, B dan C. Tipe terrain A memiliki rata-rata RMSE sebesar 19,70 dB. Tipe terrain B memiliki rata-rata RMSE sebesar 25,11 dB dan Tipe terrain $\mathrm{C}$ sebesar 26,11 dB. Jadi pada model SUI Kota Palembang termasuk pada Tipe terrain A.

Tabel 3. Perbandingan RMSE Pada Model Okumura Hata

\begin{tabular}{|c|c|c|c|c|}
\hline \multirow{2}{*}{ Site } & \multicolumn{4}{|c|}{ RMSE (dB) } \\
\cline { 2 - 5 } & $\begin{array}{c}\text { Large } \\
\text { Urban }\end{array}$ & $\begin{array}{c}\text { Small } \\
\text { Urban }\end{array}$ & $\begin{array}{c}\text { Sub } \\
\text { urban }\end{array}$ & $\begin{array}{c}\text { Open } \\
\text { Area }\end{array}$ \\
\hline 1 & 21,18 & 21,22 & 32,38 & 159,19 \\
2 & 23,83 & 23,88 & 35,07 & 161,91 \\
3 & 22,91 & 22,95 & 34,15 & 161,01 \\
4 & 21,83 & 21,88 & 33,07 & 159,92 \\
5 & 24,33 & 24,38 & 35,57 & 162,42 \\
\hline Rata-Rata & 22,82 & 22,86 & 34,05 & 160,89 \\
\hline
\end{tabular}

Tabel 4. Perbandingan RMSE Pada Model ECC-33

\begin{tabular}{|c|c|c|}
\hline \multirow{2}{*}{ Site } & \multicolumn{2}{|c|}{ RMSE (dB) } \\
\cline { 2 - 3 } & Large Urban & Medium Urban \\
\hline 1 & 24,53 & 2,83 \\
2 & 27,52 & 4,31 \\
3 & 26,26 & 3,01 \\
4 & 25,16 & 1,84 \\
5 & 27,67 & 4,42 \\
\hline Rata-Rata & 26,17 & 3,28 \\
\hline
\end{tabular}

Tabel 5. Perbandingan RMSE Pada Model Ericsson

\begin{tabular}{|c|c|c|c|}
\hline \multirow{2}{*}{ Site } & \multicolumn{3}{|c|}{ RMSE (dB) } \\
\cline { 2 - 4 } & Urban & Suburban & Rural \\
\hline 1 & 11,52 & 6,91 & 9,59 \\
2 & 11,04 & 6,12 & 8,95 \\
3 & 12,03 & 7,81 & 10,53 \\
4 & 10,18 & 7,35 & 10,99 \\
5 & 14,12 & 9,55 & 11,55 \\
\hline Rata-Rata & 11,78 & 7,55 & 10,32 \\
\hline
\end{tabular}

Tabel 6. Perbandingan RMSE Pada Model SUI

\begin{tabular}{|c|c|c|c|}
\hline \multirow{2}{*}{ Site } & \multicolumn{3}{|c|}{ RMSE $(\mathrm{dB})$} \\
\cline { 2 - 4 } & Terrain A & Terrain B & Terrain C \\
\hline 1 & 17,99 & 23,31 & 24,29 \\
2 & 20,63 & 26,23 & 27,29 \\
3 & 19,81 & 25,21 & 26,21 \\
4 & 18,84 & 24,24 & 25,24 \\
5 & 21,23 & 26,57 & 27,55 \\
\hline Rata-Rata & 19,70 & 25,11 & 26,11 \\
\hline
\end{tabular}

\subsection{Evaluasi Akurasi Model}

Grafik perbandingan RSL hasil pengukuran dengan hasil prediksi oleh keempat model pada lima site dapat dilihat pada Gambar 2, Gambar 3, Gambar 4, Gambar 5, dan Gambar 6. Nilai standar deviasi pada masing-masing site dapat dilihat pada Tabel 7. Sedangkan perbandingan rata-rata RMSE dan rata-rata standar deviasi dari keempat model disajikan dalam Tabel 8.

Berdasarkan Gambar 2, Gambar 3, Gambar 4, Gambar 5, dan Gambar 6 terlihat bahwa model ECC-33 memiliki grafik yang paling dekat dengan hasil pengukuran. Hasil ini juga dapat dikonfirmasi menggunakan data pada Tabel 8 yang menunjukkan bahwa model ECC-33 memiliki ratarata RMSE terkecil dari model yang lain, yaitu sebesar 3,28 dB, dimana RMSE terbesar bernilai 4,42 yang terukur pada site 5 dan RMSE terkecil bernilai $1,84 \mathrm{~dB}$ di site 4 . Nilai ini lebih kecil dari pada batas maksimum RMSE yang disarankan.

Parameter lain yang digunakan untuk menilai akurasi model path loss adalah nilai standar deviasi. Berdasarkan Tabel 7 dan Tabel 8 diketahui bahwa model ECC-33 memiliki rata-rata standar deviasi sebesar 2,74 dB, dimana standar deviasi terbesar bernilai 5,65 $\mathrm{dB}$ yang berada di site 1 dan standar deviasi terkecil sebesar $0,43 \mathrm{~dB}$ yang terukur di site 4. Nilai ini berada di bawah batas standar deviasi maksimum yang disarankan. Sehingga dapat disimpulkan bahwa untuk penggunaan di Kota Palembang, model ECC-33 memiliki akurasi yang cukup baik. 


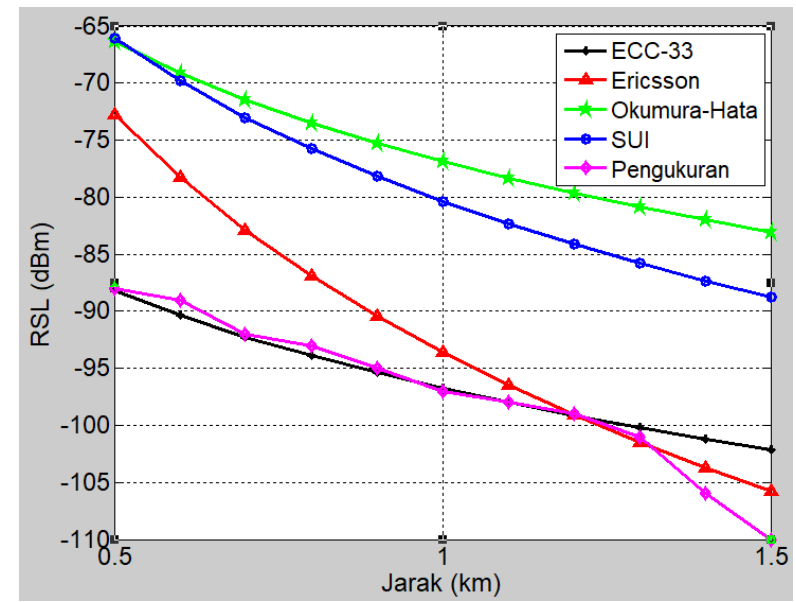

Gambar 2. Grafik RSL Pada Site 1

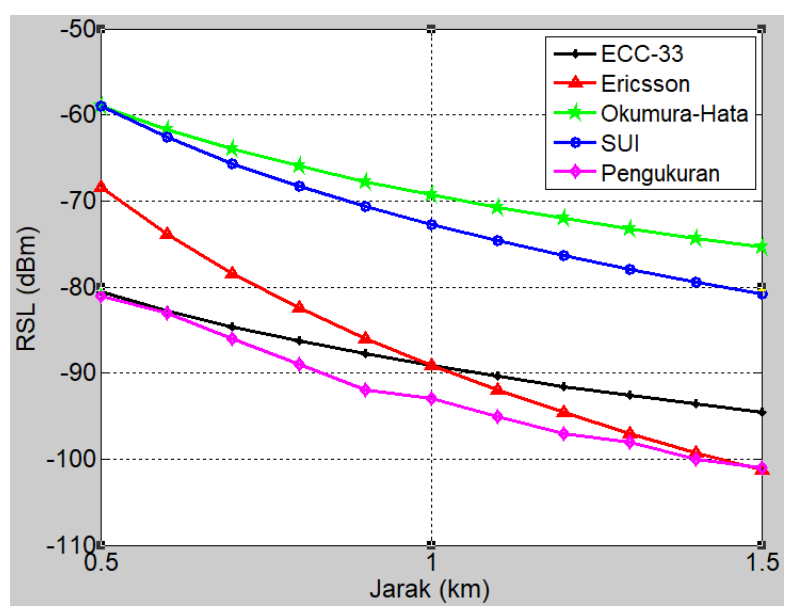

Gambar 3. Grafik RSL Pada Site 2

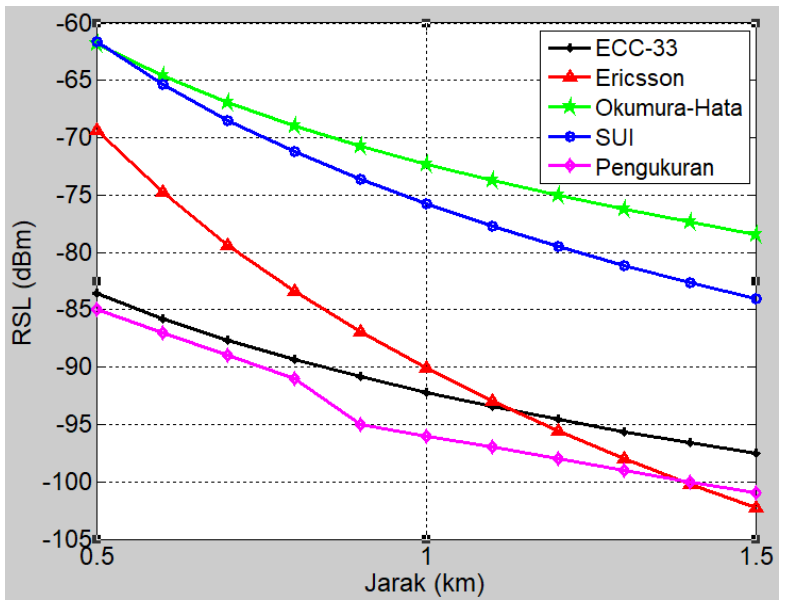

Gambar 4. Grafik RSL Pada Site 3

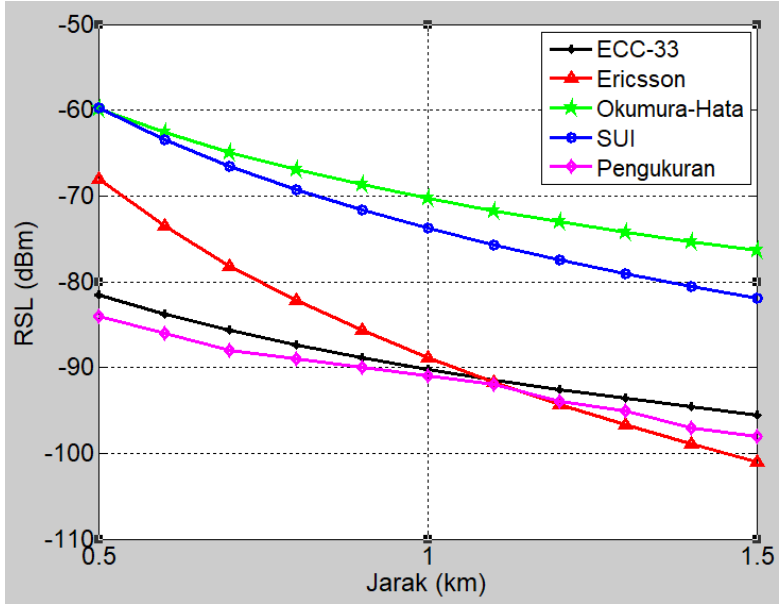

Gambar 5. Grafik RSL Pada Site 4

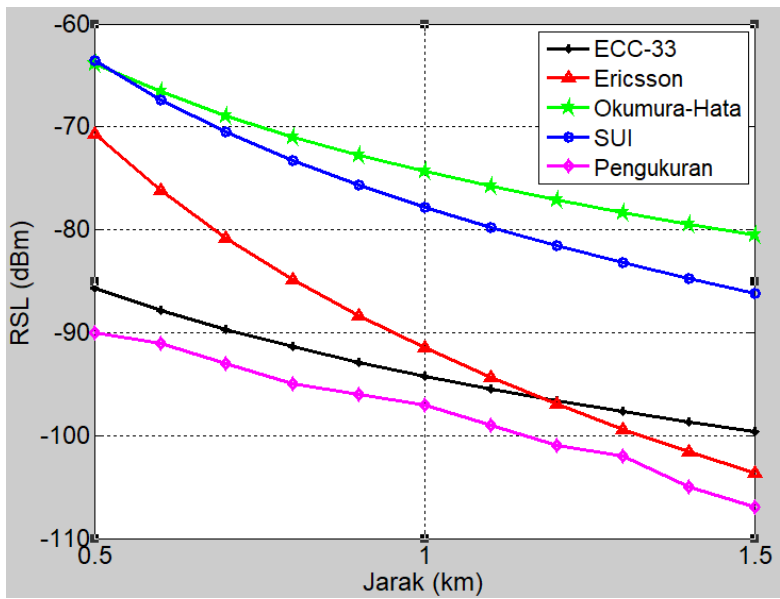

Gambar 6. Grafik RSL Pada Site 5

Tabel 7. Standar Deviasi

\begin{tabular}{|c|c|c|c|c|}
\hline \multirow{2}{*}{ Site } & \multicolumn{4}{|c|}{ Standar Deviasi (dB) } \\
\cline { 2 - 5 } & $\begin{array}{c}\text { Okumura } \\
\text { Hata }\end{array}$ & ECC-33 & Ericsson & SUI \\
\hline 1 & 5,10 & 5,65 & 20,14 & 5,08 \\
2 & 2,11 & 4,60 & 14,00 & 0,32 \\
3 & 0,42 & 1,17 & 22,70 & 3,54 \\
4 & 1,38 & 0,43 & 25,31 & 7,90 \\
5 & 1,42 & 1,87 & 27,43 & 4,93 \\
\hline Rata- & 2,09 & 2,74 & 21,92 & 4,35 \\
Rata & & & & \\
\hline
\end{tabular}

Tabel 8. Rata-Rata RMSE dan Standar Deviasi

\begin{tabular}{|c|c|c|}
\hline \multirow{2}{*}{ Model } & \multicolumn{2}{|c|}{ Parameter } \\
\cline { 2 - 3 } & RMSE $(\mathrm{dB})$ & $\begin{array}{c}\text { Standar Deviasi } \\
(\mathrm{dB})\end{array}$ \\
\hline Okumura Hata & 22,82 & 2,09 \\
ECC-33 & 3,28 & 2,74 \\
Ericsson & 7,55 & 21,92 \\
SUI & 19,70 & 4,35 \\
\hline
\end{tabular}

Model Okumura Hata memiliki rata-rata standar deviasi sebesar 2,09 dB. Nilai ini lebih kecil dari pada model ECC-33. Pada model ini standar 
deviasi terbesar ada di site 1 sebesar $5,10 \mathrm{~dB}$. Sedangkan standar deviasi terkecil sebesar $0,42 \mathrm{~dB}$ yang berada di site 3 . Namun model ini memiliki rata-rata RMSE yang cukup besar, yaitu $22,82 \mathrm{~dB}$. Nilai ini lebih besar dari pada $6 \mathrm{~dB}$ yang merupakan batas maksimum RMSE yang disarankan. Oleh karena itu, model Okumura Hata dapat digunakan sebagai alternatif model ECC-33, namun harus dioptimasi terlebih dahulu untuk meminimalkan nilai RMSE-nya.

\subsection{Optimasi Model}

Pada artikel ini yang akan dioptimasi hanya Model Okumura Hata, karena memiliki standar deviasi yang terkecil diantara model lainnya, sehingga hanya perlu mengoptimasi rata-rata RMSE-nya saja. Optimasi dilakukan dengan cara menjumlahkan path loss yang diprediksi dengan nilai rata-rata RMSE [9]. Secara matematis dinyatakan dengan persamaan (25).

$$
P L_{\text {Modified }}=P L_{\text {Okumura Hata }}+22,82
$$

Perbandingan RMSE dan standar deviasi model Okumura Hata sebelum dan setelah optimasi terdapat pada Tabel 9. Dapat dilihat bahwa setelah optimasi rata-rata RMSE model ini menurun menjadi $1,75 \mathrm{~dB}$ dan rata-rata standar deviasi menjadi 0,67 dB. Sehingga setelah optimasi model Okumura Hata dapat memprediksi path loss di Kota Palembang dengan akurasi yang tinggi.

Tabel 9. RMSE dan Standar Deviasi Okumura Hata Sebelum dan Sesudah Optimasi

\begin{tabular}{|c|c|c|c|c|}
\hline \multirow{2}{*}{ Site } & \multicolumn{2}{|c|}{ RMSE (dB) } & \multicolumn{2}{c|}{ Standar Deviasi } \\
\cline { 2 - 5 } & $\begin{array}{c}\text { Sebelum } \\
\text { Optimasi }\end{array}$ & $\begin{array}{c}\text { Sesudah } \\
\text { Optimasi }\end{array}$ & $\begin{array}{c}\text { Sebelum } \\
\text { Optimasi }\end{array}$ & $\begin{array}{c}\text { Sesudah } \\
\text { Optimasi }\end{array}$ \\
\hline 1 & 21,18 & 2,87 & 5,10 & 0,76 \\
2 & 23,83 & 1,75 & 2,11 & 0,67 \\
3 & 22,91 & 0,65 & 0,42 & 0,16 \\
4 & 21,83 & 1,56 & 1,38 & 0,46 \\
5 & 24,33 & 1,90 & 1,42 & 1,32 \\
\hline Rata- & 22,82 & 1,75 & 2,09 & 0,67 \\
Rata & & & \multicolumn{2}{c}{} \\
\hline
\end{tabular}

\section{Kesimpulan}

Berdasarkan perbandingan RSL pengukuran dan hasil prediksi, didapatkan kategori lingkungan yang sesuai untuk Kota Palembang. Pada model Okumura Hata digunakan kategori lingkungan large urban, sedangkan pada model ECC-33 digunakan kategori medium urban. Pada model Ericsson, digunakan kategori suburban, dan untuk model SUI digunakan kategori terrain A.
Berdasarkan hasil pengukuran pada lima site di Kota Palembang, model ECC-33 merupakan model dengan akurasi yang paling bagus. Hal ini dibuktikan dengan nilai rata-rata RMSE-nya yang paling kecil diantara tiga model lainnya. Selain itu model ECC-33 juga memiliki rata-rata standar deviasi yang lebih kecil dari pada model Ericsson dan model SUI. Rata-rata RMSE dan rata-rata standar deviasi model ECC-33 juga berada di bawah batas maksimum yang disarankan.

Model Okumura Hata memiliki rata-rata standar deviasi yang terkecil dibandingkan tiga model lainnya. Akan tetapi model ini memiliki ratarata RMSE sebesar $22,82 \mathrm{~dB}$, dimana nilai ini melebihi batas maksimum yang disarankan sehingga perlu dioptimasi. Setelah dioptimasi, ratarata RMSE model ini berkurang menjadi 1,7 dB dan standar deviasi menjadi 0,67 dB. Jadi model Okumura Hata yang telah dioptimasi dapat memprediksi path loss pada lima site yang diukur dengan akurasi yang tinggi.

\section{Daftar Pustaka}

[1] A. R. Mishra, Fundamentals of Network Planning and Optimisation - $2 G / 2.5 G$ $/ 3 G / 4 G$...Evolution to $5 G 2^{\text {nd }}$ edition. 2018.

[2] W. Lambrechts and S. Sinha, Terrestrial and Millimeter-Wave Mobile Backhaul: A Last Mile Solution, vol. 77. 2019.

[3] J. Milanovic, S. Rimac-Drlje, and K. Bejuk, "Comparison of propagation models accuracy for WiMAXon3.5GHz," in Proceedings of the IEEE International Conference on Electronics, Circuits, and Systems, 2007, pp. 111-114, doi: 10.1109/ICECS.2007.4510943.

[4] K. Fujimoto, Mobile Antenna Systems Handbook 3rd edition. 2008.

[5] J. C. Ogbulezie, M. U. Onuu, J. O. Ushie, and B. E. Usibe, "Propagation Models for GSM 900 and $1800 \mathrm{MHz}$ for Port Harcourt and Enugu, Nigeria," Netw. Commun. Technol., vol. 2, no. 2, pp. 1-10, 2013, doi: $10.5539 /$ nct.v2n2p1.

[6] O. F. Oseni, S. I. Popoola, R. O. Abolade, and O. A. Adegbola, "Comparative Analysis of Received Signal Strength Prediction Models for Radio Network Planning of GSM $900 \mathrm{MHz}$ in Ilorin, 
Nigeria," Int. J. Innov. Technol. Explor. Eng., no. 3, pp. 2278-3075, 2014, [Online]. Available:

http://citeseerx.ist.psu.edu/viewdoc/downlo ad?doi=10.1.1.676.1258\&rep=rep1\&type $=$ pdf.

[7] K. M. Udofia, N. Friday, and A. J. Jimoh, "Okumura-hata propagation model tuning through composite function of prediction residual," Math. Softw. Eng., vol. 2, no. 2, pp. 93-104, 2016.

[8] Rakesh. N and K.Srivasta, "A Study on Path Loss Analysis for GSM Mobile Networks for Urban, Rural and Suburban Regions of Karnataka State," Int. J. Distrib. Parallel Syst., vol. 4, no. 1, pp. 53-66, 2013, doi: 10.5121/ijdps.2013.4105.

[9] P. K. Sharma, D. Sharma, P. C. Sau, and A. Gupta, "Comparative analysis of propagation models in LTE networks with spline interpolation," in 2nd International Conference on Communication, Control and Intelligent Systems, CCIS 2016, 2017, pp. 3-7, doi: 10.1109/CCIntelS.2016.7878189.

[10] S. Tahcfulloh and E. Riskayadi, "Optimized Suitable Propagation Model for GSM 900 Path Loss Prediction," TELKOMNIKA Indones. J. Electr. Eng., vol. 14, no. 1, 2015, doi: 10.11591/telkomnika.v14i1.7470.

[11] M. P. A. Simarmata, S. Soim, and M. Fadhli, "Analisa Link Budget Dengan Perbandingan Pemodelan Propagasi Pada Komunikasi Selular Daerah Urban," $J$. Elektro dan Telekomun. Terap., vol. 5, no. $2, \quad$ p. 712, 2019, doi: 10.25124/jett.v5i2.1989.

[12] T. S. Rappaport, Wireless Communications,Principles and Practice. 2002.

[13] A. Aragon-Zavala, Indoor Wireless Communications. 2017.

[14] A. Zreikat and M. Dordevic, "Performance Analysis of Path loss Prediction Models in Wireless Mobile Networks in Different Propagation Environments," in Proceedings of the 3rd World Congress on Electrical Engineering and Computer Systems and
Science, 2017, no. June, doi: 10.11159/vmw17.103.

[15] M. Shahajahan and a Q. M. A. Hes-shafi, "Analysis of Propagation Models for WiMAX at $3.5 \mathrm{GHz}$, ".2009.

[16] R. J. Hyndman and A. B. Koehler, "Another Look at Measures of Forecast Accuracy," Int. J. Forecast., vol. 22,November, pp. 679-688, 2005, doi: 10.1016/j.ijforecast.2006.03.001.

[17] R. Verma and G. Saini, "Statistical tuning of Cost-231 Hata model at $1.8 \mathrm{GHz}$ over dense urban areas of Ghaziabad," in Proceedings of the 10th INDIACom; 2016 3rd International Conference on Computing for Sustainable Global Development, INDIACom 2016, 2016, pp. 1220-1225, Accessed: Apr. 14, 2020. [Online]. Available: https://ieeexplore.ieee.org/document/77244 61.

\section{Biodata Penulis}

Mohammad Fadhli, menyelesaikan pendidikan S1 di UNP Padang dan S2 di ITS Surabaya. Saat ini bekerja sebagai dosen di Jurusan Teknik Elektro Politeknik Negeri Sriwijaya.

Sopian Soim, menyelesaikan pendidikan S1 di Universitas Sriwijaya Palembang dan S2 di ITS Surabaya. Saat ini bekerja sebagai dosen di Jurusan Teknik Elektro Politeknik Negeri Sriwijaya. 